\title{
TOP MANAGEMENT LEADERSHIP: INSIDE THE BLACK BOX
}

\author{
J. G. HUNT* \\ Texas Tech University \\ KIMERLY B. BOAL \\ Texas Tech University \\ RITCH L. SORENSON* \\ Texas Tech University
}

\begin{abstract}
Based on leadership categorization theory from the cognitive sciences, a partial model of top management leadership is developed. The model looks inside the leadership black box and considers the personal and organizational consequences of matches and mismatches between three levels (superordinate, basic and subordinate) and two dimensions (substantive/content and symbolic/process) of leadership category prototypes and perceived leadership behaviors. The model also considers the impact of environmental, industry, organizational and personal background variables on the leadership category prototypes. The prototype/behavior match notion is explicated in considerable conceptual and empirical detail to encourage future research and the research implications of the model in general are discussed.
\end{abstract}

Approaches to top-management leadership frequently have tended to use an input/output conceptualization or at best an input/throughput/output conceptualization with throughputs treated as a black box. However, work from the cognitive sciences suggests that if we are truly to understand leadership at the strategic or any other level we must understand what is in the black box (Gardner, 1985).

*Direct correspondence to: any of the authors at: College of Business Administration, Texas Tech University, Lubbock, Texas 79409-4320.

Leadership Quarterly, Volume 1 Number 1, pages 41-65.

Copyright (C) 1990 by JAI Press Inc.

All rights of reproduction in any form reserved.

ISSN: $1048-9843$. 
The purpose of this paper is to extend recent cognitively-oriented leadership work into a model linking leadership, cognitive processes, and individual and organizational outcomes at the top management level referred to as the dominant coalition (Cyert \& March, 1963), strategic apex (Mintzberg, 1983), or upper echelon (Hambrick \& Mason, 1982). While many of our ideas would be applicable to other organizational levels, we agree with many others, e.g., Hambrick and Mason (1982), that organizational strategies and effectiveness reflect the values and perceptions, and for us in particular, the implicit theories of leadership (leadership prototypes) (discussed below), of powerful actors in an organization. Furthermore, a recent reanalysis of previous studies (Day \& Lord, 1988), suggests that as much as $45 \%$ of an organization's performance is a function of top management leadership, thus emphasizing the importance of getting inside the black box. Specifically, we examine the implications of our model and its black box for leader selection and both individual and organizational outcomes.

\section{INSIDE THE BLACK BOX: IMPLICIT LEADERSHIP THEORIES AND LEADERSHIP PROTOTYPES}

Both research in personality theory (Shweder, 1975, 1982) and a book on implicit psychology (Wegner \& Vallacher, 1977) argue that individuals develop implicit theories (implicit in the sense of not being spelled out) to give meaning to events, to attribute causes to phenomena, and to see pattern and regularity in the world around them. These personal theories undoubtedly account for the continued proliferation of different approaches to leadership (e.g., Miner, 1984).

Recently, researchers have obtained considerable evidence that perceptions of leaders are influenced by implicit or "folk" thcories of leadership (e.g., Eden \& Leviation, 1975; Rush, Thomas \& Lord, 1977). Borrowing from the concept of folk theories of work behavior articulated by Borman $(1983,1987)$, implicit leadership theories (ILT's are seen as personal constructs used to make judgments about leadership and effective/ineffective leaders or leaders/non-leaders (cf. Korukonda \& Hunt, 1989). These perceptual sets of frames of reference influence perception and interpretation of information as well as observations and judgments about other people (Duck, 1982).

Lord and his colleagues (e.g., Lord, 1985; Lord, Foti \& Phillips, 1982; Lord, Foti \& DeVader, 1984; Rush, Thomas \& Lord, 1977) have proposed a leadership categorization theory to articulate the cognitive structure underlying such ILT's. As we show more fully in the next section, a key concept of ILT's and leadership categorization theory is that of leadership prototypes. These prototypes ("best exemplars") highlight modal or central tendencies of a leadership category which differentiate effective/ineffective leaders or leaders/non-leaders. Individuals store prototypes inside their heads and use them to select and pare down information being processed concerning various aspects of leadership (e.g., Hastie, 1981; Lord, et al., 1982). As Cantor, Smith. French and Mezzich (1980) suggest, individuals are placed into fuzzy set categories by comparing them to the prototypical individual of each category. When the fit is close, the target is assessed rapidly and with confidence. When the fit is loose, evaluation takes longer and is accompanied by uncertainty. We argue below that ILT's differ both in terms of their level of specificity (i.e., superordinate/supra-industry; basic/industry; and subordinate/organizational) and 
domain or dimensionality (i.e., substantive/content versus symbolic/process). Furthermore, the development of ILT's is influenced differentially by environmental, industry, organizational, and individual level variables.

Of special importance for the purposes of our model is the match between one or more individual's leadership prototypes and the person being evaluated. This match has three implications. The first has to do with the likelihood of being selected for a leadership position. Building on the work of Sackett and Dreher $(1982,1984)$, we posit that the more a leadership candidate's perceived behavior matches the selector's leadership prototype the more likely the candidate will be chosen. Recent research on assessment center ratings (Russell, 1987) lends support to this contention.

The second implication involves the subordinates' reaction to an individual in a leadership position. We argue that when subordinates observe acts of their superior, they note particularly salient characteristics and compare these against their own leadership prototypes. If there is a match, the stimulus person is more likely seen as a "real leader", "leader", or "effective leader". Where there is not a match, the leader is more likely seen as the opposite.

Moreover, we hypothesize that the manager who is seen as a real leader is in an advantageous position vis-a-vis subordinates as compared with a manager seen as a nonleader. Managers who match subordinates' leadership prototypes should receive increased social power, higher quality manager-subordinate exchanges, and more credit for work outcomes (Cronshaw \& Lord, 1987; Seers \& Graen, 1984). At the same time, we expect that subordinate performance and human resource maintenance outcomes such as satisfaction, commitment, turnover, and absenteeism (see Schermerhorn, Hunt \& Osborn, 1988) should be positively affected. As a final implication, we argue that while there is not a direct link between individual-level performance and organizational effectiveness, organizations may be more effective when leadership prototypes are consistent with environmental demands.

\section{LEADERSHIP CATEGORIZATION THEORY}

As previously mentioned, Lord and his colleagues (1982, 1984) proposed a leadership categorization theory to articulate the cognitive structure underlying ILT's. Here, "the perceiver is viewed as an active selector/organizer of stimulus information rather than a passive receiver of stimulus characteristics" (Lord et al., 1984, p. 345).

Lord and his associates, who base their theory on the work of Rosch (1978) and her associates, contend that all individuals divide their surroundings into categories to provide cognitive economy. Preserving information in categories allows nonidentical stimuli to be treated as "equivalent." For example, individuals group certain attributes of real world objects together, e.g., creatures with features are expected to be more likely to fly than creatures with fur. Such categorization is called "perceived world structure" (Lord et al. 1982 , p. 106).

\section{Category Structures}

Rosch (1978) argues that category systems can be structured along both vertical and horizontal dimensions. The vertical dimension is based on the degree of inclusiveness 
(number of different kinds of stimuli that can be classified into the same category). The horizontal dimension differentiates categories at the same vertical level. Each horizontal category member has a "family resemblance:" a number of attributes in common with one or more other members, but few attributes are common to all the members of the category (Lord et al., 1982, p. 106). Lord and his associates apply these concepts in their leadership categorization model as shown in Figure 1. Figure 1 summarizes the vertical aspects of leadership categories into superordinate, basic, and subordinate levels.

Superordinate Level. This level is the most inclusive classification level as it simply refers to attributes separating leaders from non-leaders. Family resemblance suggests that there are a few attributes common to all leaders. At the same time, the attributes common to leaders, and hence best characterizing the superordinate category "leader," should have minimal overlap with those of the superordinate category "non-leader".

For example, Lord et al. (1982) found in one study that a prototype which separated leaders from non-leaders consisted of decisiveness, intelligence, and industriousness. These results are consistent with other empirical evidence that suggests that all leadership positions share certain common features and thus the possession of some specific traits is necessary in all leadership positions (cf. House \& Baetz, 1979).

Basic and Subordinate Levels. These categories are less inclusive than categories at the superordinate level. Basic-level categories reflect a wide range of real world leaders (see Figure 1). Note that at this level the leader/nonleader category takes into account broad leadership situations. As applied in a top-management context, basic-level categories might be seen as encompassing prototypes of leaders in different institutional settings (e.g., Lammers \& Hickson, 1979); for example, hospitals, education, banks, manufacturing, etc, and industry characteristics; for example, degree of regulation, concentration, and competiveness.

Lord et al. (1984) argue that subordinate-level categories are the least inclusive level. As shown in Figure 1, these represent a subdivision of the basic level category. At the top leadership level, we might think of leadership prototypes within particular organizations or as influenced by particular organizational structure, strategy, and life cycle (developed in more detail below). While leader attributes have been emphasized as prototypes at the superordinate and basic levels, Lord et al. (1984) argue that exemplar

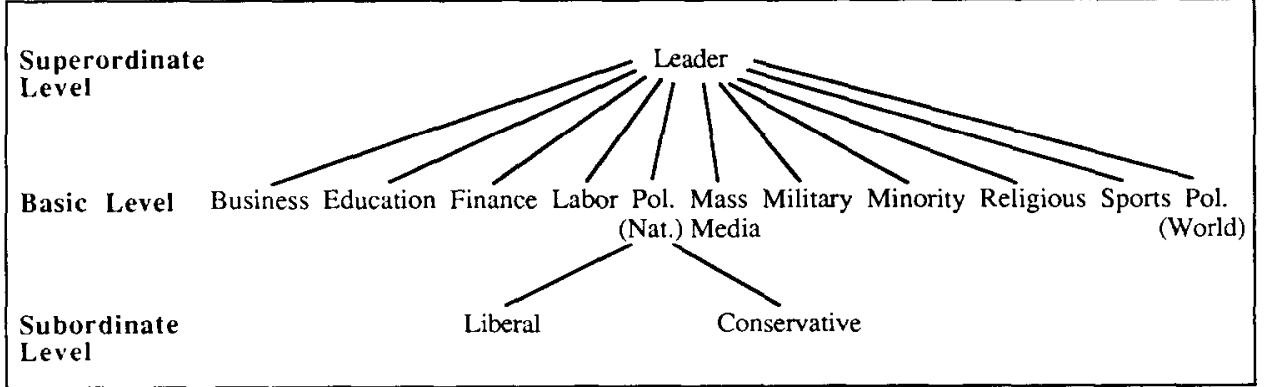

Figure1: Lord et al. (1984) Tentative Hierarchy of Leadership Categories

(used with permission) 
representations which refer to specific people (e.g., He is like a "Little Hitler.") might be a plausible alternative or additional conceptualization to use at the subordinate level. Note for example, Fortune magazine's (1989) recent article on the toughest bosses to work for.

Prototypes fall under the general category of schemas. Specifically, they can be categorized as a type of person schema (Lord \& Foti, 1986). Their hierarchical nature is very similar to that of scripts - another kind of schema (cf. Lord \& Foti, 1986). Using such script schemas, Hunt, Baliga and Peterson (1988) discuss supra-industry (superordinate), industry (basic) and organization (subordinate) level script schemas utilizing arguments not unlike those here, further emphasizing the importance of the hierarchical level notion.

Domain. Besides different levels of inclusiveness, we hypothesize that ILT's differ horizontally in terms of their domain. researchers such as Jacobs and Jaques (1989 in press), Perrow (1979) and Romanelli and Tushman (1983) suggest that leaders (especially those at the top level) can have direct and indirect effects on organizational outcomes. They can have direct effects when they act within the substantive domain by their choices of markets and strategies, securing and allocating resources, designing organization structures, etc. They can have indirect effects, deep within the organization, when they operate in the symbolic domain by articulating values and their choice of language and communication patterns.

Indeed, symbolic aspects have recently been given special attention by those such as Romanelli and Tushman (1988) and Meindel and his colleagues (Meindel, Ehrlich \& Dukerich, 1985; Meindel \& Ehrlich, 1987). The former argue that the relative emphasis on symbolic versus substantive leadership is a function of organizational evolution - that is, whether the organization is stable or undergoing a reorientation. Reorientation periods call for heavier stress upon both substantive and symbolic aspects while stability emphasizes symbolic actions (Romanelli \& Tushman, 1988).

Meindl and associates argue that there is a strong tendency for people to think in terms of symbolic aspects of leadership to explain complex occurrences that are otherwise inexplicable. In other words, leadership is invoked as an explanation where the "real" causes are complex and/or unknown. These authors argue that this symbolic use of leadership is quite pervasive and extremely important in our society. A frequently occurring illustration is where a baseball manager is fired and a new one hired with great fanfare as a public symbol that "new leadership" will now improve the team's performance. It here almost goes without saying, that the manager's "real" impact on performance vis-a-vis other factors is virtually impossible for the team owner to determine so the manager is used as a symbolic scapegoat.

In terms of prototype domain, we use the labels substantive/content and symbolic/process to characterize the two previously discussed dimensions. Other labels might be substance versus style or content versus process. The substantive/content label is chosen to highlight the fact that individuals often assume similarity between the issue at hand (e.g., change product focus) and the traits, skills, background (e.g., a background in marketing versus human resources) necessary for a person to address the issue successfully. We use the symbolic/process label to include current, non-trait, classifications of leadership approaches that emphasize either or both transformational or transactional aspects (e.g., Bass, 1985). 


\section{FACTORS INFLUENCING PROTOTYPES AT THE TOP MANAGEMENT LEVEL}

Starting at the left side of the model in Figure 2, we consider factors involved with the development of category prototypes. Discussion of such factors appears to be relatively sparse in the literature although Gioia and Poole (1984) touch on ways in which script schemas are acquired. For present purposes we follow the suggestion of Day and Lord (1988), and focus primarily on macro-level variables that seem to us to be particularly important (although we do discuss briefly macro-micro background variables). It is also important to note that we are here dealing with prototypes of those immediately below the CEO.

\section{Superordinate Prototype Level}

At the superordinate category prototype level we see environment and societal culture as having a potentially strong impact on the development of prototypes/LT's, especially along the process dimension. While there are many conceptualizations of environment (e.g., Duncan, 1972; Jurkovich, 1974; Terreberry, 1968), a simple dichotomy between general and task or specific environment (Dill, 1958) will suffice for present purposes.

General Environment and Societal Culture. The general environment is geographically bounded and includes socio-economic, education, and legal-political segments. Relevant geographical boundaries for the general environment may be as narrow or wide as needed for any given purpose. For our purpose we think the boundaries should be reflective of environmental forces at the broad national or societal level.

As a component of the general environment (Osborn, Hunt, \& Jauch, 1980), we think societal culture will have an important impact on superordinate leadership category prototypes, particularly along the symbolic/process dimension. At the superordinate prototype level, we believe that culture specific prototypes are developed that reflect shared ideologies and values that govern collective behavior. For example, Sathe (1985) suggests that in every culture there are important, shared assumptions that are manifest in what individuals have in common with respect to objects, talk, behavior, and emotions.

Starbuck (1976) has argued that since it is virtually impossible to sort out events causally, individuals tend to observe, interpret, and learn what they already believe (i.e., ideologies) or, we may add, want to believe (i.e., values). Or as the great artist Constantin Stanislawski is reported as saying "truth cannot be separated form belief nor belief from truth."

The importance of ideologies/values as a determinant of superordinate prototypes depends on their strength. Stewart (1982) suggested that we can view top management leadership as having three components: demands (what must be done), contraints (that limit what can be done), and choices (discretion in choosing what to do or how to do it). Some situations are so demanding (powerful), with respect to situational cues and incentives to behave, that we expect virtually everyone would view the situation similarly and have uniform beliefs regarding appropriate behaviors (cf. Mischel, 1977).

On the other hand, Hambrick and Finkelstein (1987) argue that many situations are conducive to the exercise of management discretion. Here, we would expect the emergence of more diverse and idiosyncratic prototypes. It is interesting to note that some would argue that the task of top management . . . "is (to) create and maintain systems of shared 


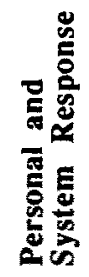
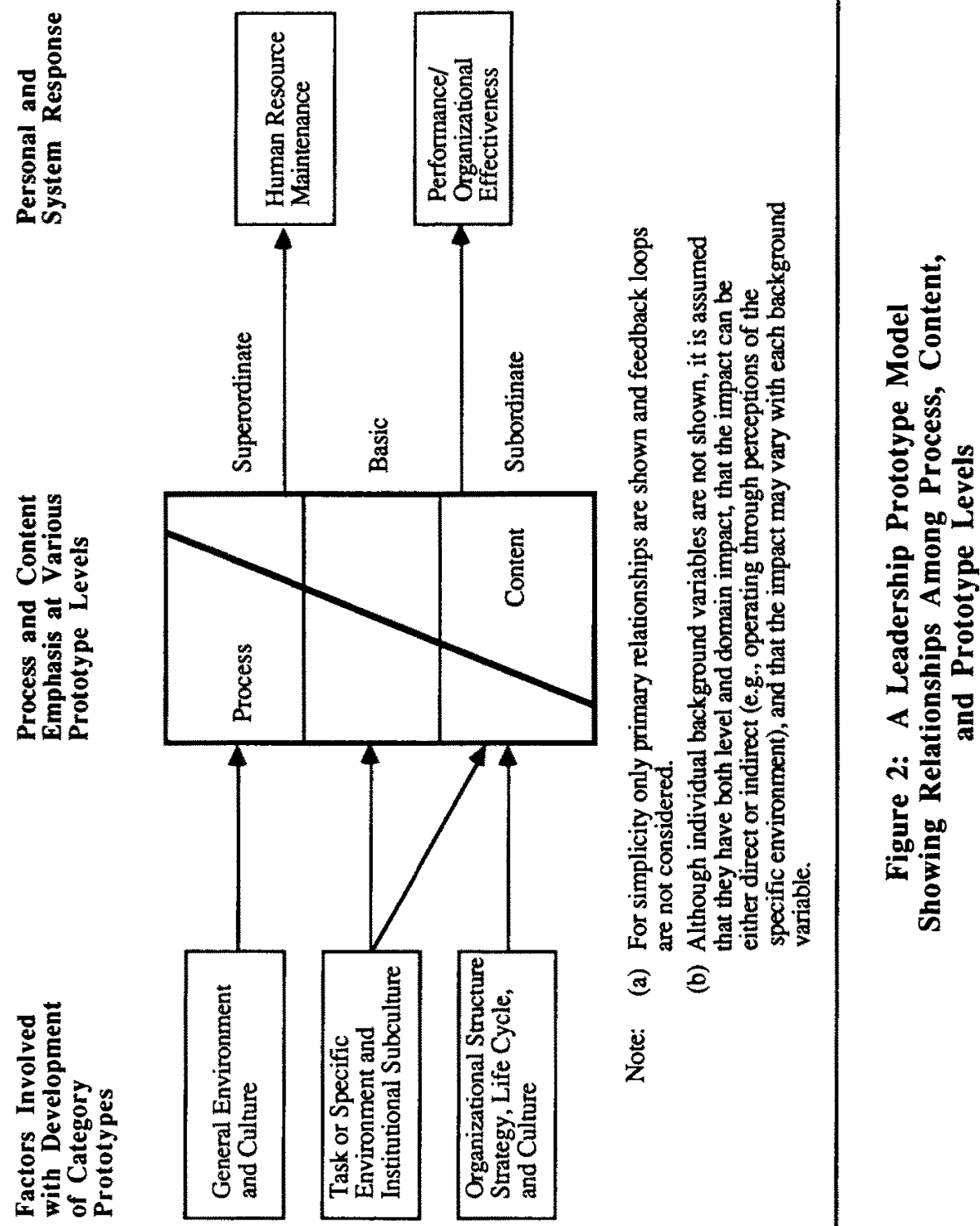
meaning that facilitate organized action" (Smircich \& Stubbart, 1985, p. 724), or from our more limited perspective, to create shared superordinate prototypes.

Research by Ronen and Shenken (1985) demonstrates that it is possible to cluster countries meaningfully in terms of cultural variables such as values and needs. We expect different superordinate prototypes to emerge as a function of ideology and value. For example, in the United States, a dominant cultural value is reflected in our political system, which holds that leaders, as opposed to non-leaders, are participative.

Research by Hornstein, Heilman, Mone, and Tartell (1987) supports the previous contention. Conversely, based on Hofstede $(1976,1980)$ we would not expect a participative prototype to be universally found. Rather, in some countries, e.g., Brazil, we might expect the predominance of an autocratic prototype (cf. Farris \& Butterfield, 1973).

While we have implied that in the case of strong cultures, superordinate prototypes are widely shared, clearly not all cultures are strong or uniform. In situations where the culture is weak or multiple cultures vie with one another, (e.g., in multi-national corporations-MNCs), we expect wide variance among individual superordinate prototypes because of a clash of cultures or leadership prototypes between the origin of the organization's home country and the location of operations.

For example, a recent study of American and Japanese firms (Yeh \& Sagafi-nejad, 1987) found that these organizations exported their organizational cultures to a third country, Taiwan. Furthermore, approximately 80 percent of both American and Japanese firms resisted Taiwanese acculturation even though they had been operating in Taiwan for more than 10 years. How strong the clash, and therefore, how large the effect in terms of leader selection or evaluation depends on how congruent is the value system between the home and operating country(ies). Thus, based on Ronen and Shenken (1985), we expect smaller cultural differences in superordinate prototypes between, say, Americans and Canadians than between Amcricans and Japancse.

Such differences should influence how expatriate managers are evaluated. A study by Eshghi (1985) of Japanese firms operating in the United States lends support to this contention. He found that managers evaluated their Japanese subordinates more highly than they did their American subordinates. As he states, ". . . it seems that although practices of management in the Japanese-owned firms in the U.S. have been changed, the perceptions of Japanese expatriate managers in the U.S. regarding appropriate kinds of behavior in the work organization have not (p. 95)." We contend that cultural differences in superordinate prototypes help explain these results.

In terms of our model, the congruency between the superordinate prototypes of managers should affect the probability of selection. For example, we conjecture that a Mexican MNC would choose a Mexican national or a Latin American to run an overseas subsidiary in, say, Greece, before the MNC would choose one of its Greek nationals to head up operations in Greece. Second, because Latin American and Near Eastern cultures are significantly different (Ronen \& Shenken, 1985), we expect that Greek subordinates would react negatively to the foreign manager's leadership.

\section{Basic Prototype Level}

We turn now to influences on the basic leadership category prototype in Figure 2 and propose that the task or specific environment is one such influence.

Specific Environment. This environmental segment consists of those organizations with 
which a focal organization must interact to grow and survive (Hunt, Osborn \& Martin, 1983). As such, the specific environment will tend to reflect institutional forces and is not geographically bounded. We expect these forces to be less widespread and more institutionally specific than those from the general environment.

Institutional Subculture. Culture literature tends to concentrate primarily on societal or organizational culture (cf. Smircich, 1983). Typically, there is not an intermediate level that corresponds directly with the industry or institutional level. Conceptually, however, we think it is important to include such a concept, which we have labeled "institutional subculture."

Such a subculture corresponds to what Astley (1985) refers to as an organizational community. An organizational community consists of organizations that produce similar types of products or services (e.g., educational institutions; automobile manufacturers). Within each organizational community we would expect similar core technologies (Thompson, 1967) which would determine the dominant competencies (McKelvey, 1982) necessary for survival.

Since dominant competencies are carried by people, the need to acquire these would lead members of the same organizational community to recruit new members from the same "compool" (a common pool of employees, customers, regulators, etc.) of applicants (McKelvey, 1982). Furthermore, as Astley (1985) points out, over time, organizations within this same community begin to exchange resources more and more with each other. This exchange includes people, belief systems, and values. We suggest that this exchange would lead to greater homogeneity of leadership prototypes, particularly in highly concentrated industries.

Similarly, following our earlier discussion of Hunt et al's (1988) notion of industry script schemas, we argue that different basic (industry-level) prototypes exist. Thus, for example, we conjecture that a different, widely held, prototype exists in the automobile industry than in the health care industry. These differences could account for the fact that successful executive transference is problematic (Shetty \& Peery, 1976) and why mergers between related firms are more likely to be successful than mergers between unrelated firms (Malekzadeh \& Nahavandi, 1987).

Analogous to the concept of organizational communities is the concept of occupational communities. As discussed by Van Maanen and Barley (1984), occupational practices, values, vocabularies, and identities are transmitted to members and influence careers far beyond the boundaries of any particular organization. Thus, while being a professor at a particular university may have particularistic meaning and implications, the more general set of skills, beliefs, and understandings associated with being a professor transcend employment at a given institution and serve to define what is meant by excellence.

We suggest that the practices and requirements of occupational communities are particularly relevant to the substantive/content domain of ILTs. Note for example, how often department heads or deans are chosen not because of their symbolic or process skills, but because they have demonstrated good research skills (a substantive, but possibly irrelevant, domain).

\section{Subordinate Prototype Level}

We expect organizational structure, strategy, life cycle, and organizational culture to be particularly important influencers of subordinate-level leadership category prototypes. 
Organizational Structure. There are many different typologies for conceptualizing, categorizing, and measuring organizational structure. It is not our intent to join into the many arguments relating to them. Rather, it is our contention that the organization's structure influences the development of subordinate leadership prototypes.

Thus, we hypothesize, other things equal, that individuals in similarly structured organizations should have similar subordinate-level prototypes. We draw upon Miner's (1980) work for illustrative purposes. As he states, "my view is that different systems of organizing human work have inherent approaches to inducing human effort in pursuit of the organization's goals and, thus, different concepts of the leadership role' (1982, p. 296).

Miner (1980) describes four different types of organizations. They are: 1) hierarchic or bureaucratic systems; 2) professional or knowledge-based systems; 3) task or entrepreneurial systems; and 4) group or socio-technical systems.' Also, he describes four corresponding types of role motivation. His basic proposition is that for each system of organization a certain type of individual, i.e., one who possesses the appropriate role motivation, should be evaluated among the leaders.

Furthermore, he suggests that good (i.e., valued high performing) leaders, as opposed to poor leaders, are more likely to be properly matched (e.g., professional system with professional role motivation). Research with respect to hierarchical and professional systems supports Miner's contention (e.g., Miner, 1982). Though Miner did not use prototypes per se, to us his research is suggestive of them. Based upon the work of Burns and Stalker (1961), we believe structure will have its greatest impact on the symbolic dimension of ILTs.

Strategy. Is is important to recognize that organizations and leadership prototypes are bound together at the basic prototype level by the organization's societal function (e.g., production of knowledge prototype of an educational leader). Thus, as alluded to above, we expect educational institution prototypes to share some common features not found in other organizations at the basic prototype level. However, strategy, a major concern of top management leaders, is not limited simply to the organization's goals and objectives but also is concerned with the means for achieving those goals.

Hence, even within common basic prototypes, e.g., business, we expect to find differences. For example, Miles and Snow (1978) have identified four different mechanisms business organizations can utilize for adapting to and achieving goals related to their entrepreneurial, engineering, and administrative problems. These authors labeled these types (mechanisms) defenders, analyzers, prospectors, and reactors. ${ }^{2}$ Furthermore, Miles and Snow suggest that different theories of management (for us similar to leadership prototypes) emerge and are appropriate for each strategic type.

For example, these authors suggest that firms adopting a prospector strategy should select for leadership positions individuals with marketing and product development backgrounds. In contrast, firms pursuing a defender strategy should select as leaders managers with experience in production and finance. If, as Miles and Snow assert, strategies, over time, arc self-reinforcing, this would explain why leadcrs tend to be succeedcd by individuals with similar backgrounds (Smith \& White, 1987) and why organizations tend generally to select insiders, as opposed to outsiders, for executive succession (Vancil, 1987). This is true, even when low levels of organizational performance suggest that an outsider (with a different prototype) is called for (cf. Dalton \& Kesner, 1985; Hofer, 
1980; Lubatkin \& Chung, 1985; Schwartz \& Menon, 1985; Starbuck \& Hedberg, 1977).

Of course, the causal arrow can go both ways. Thus, a firm whose strategic apex is dominated by engineering types would be likely to adopt a defender strategy. However, firms dominated by entrepreneurial types would tend to adopt a prospector strategy. A recent study by Smith, Guthrie and Chen (1986) found support for the idea that firms with different strategic orientations emphasized different functional skills in selecting key executives. Furthermore, Zahra (1985) found significant differences in the managerial beliefs, philosophies, and goals among each of Miles and Snow's four strategic types.

In addition to the research of Miles and Snow, other collaborative research using different strategic typologies supports the contention that different subordinate-level prototypes are likely to exist in organizations that pursue different strategies. Herbert and Deresky (1987), for example, found that whether a firm followed a develop, stabilize, or turnaround strategy greatly related to the activities, skills, and orientations of the managers they studied.

Similarly, Gupta and Govindarajan (1982) found differences between managers, at the SBU level of analysis, depending upon whether they followed a build, hold, harvest, or divest strategy. Filley and Aldag (1978) also found that leadership aspects varied depending upon whether the organization followed a craft, promotion, or administrative strategy.

Some (e.g., Gerstine \& Reisman, 1983) have even developed detailed specifications of ideal candidates for general managers depending on the organization's strategic situation. For us, the previously cited material provides a clear indication that strategy influences the prototypes that at least some individuals develop, especially on the substantive/content dimension. Furthermore, there is likely to be wide variance on this dimension of ILTs at the basic and subordinate levels.

Again, while there are many different conceptualizations of strategic types, for illustrative purposes in our model, we use a simple one. Consistent with previous discussion, we argue that one should expect subordinate-level prototypes to differ as a function of whether the chosen strategy emphasizes high growth, high profitability, or turnaround. Based on Lowin and Craig (1968), we hypothesize that on the symbolic/process dimension, prototypes emphasizing dynamic participation will be found in growth-oriented firms, but the prototypes for turnaround-oriented firms will be autocratic.

Organizational life Cycle. Various scholars (e.g., Kimberly \& Quinn, 1984; Quinn \& Cameron, 1983) suggest that organizations pass through stages, much as do biological organisms. This organizational life cycle is often described in terms of birth, growth, maturity, and revitalization or death (cf. Morrison \& Bauerschmidt, 1987). Both Quinn and Cameron (1983) and Baliga and Hunt (1988) suggest that since the criteria for effectiveness vary across organizational life cycles, the leadership traits, skills, and behaviors appropriate in one stage may not be appropriate in another. For example, Quinn and Cameron (1983) emphasize the importance of the leader's ability to acquire resources in the birth stage.

Since venture capitalists are heavily influenced by the leader's background in their decision to invest money (Sandberg, 1986), this emphasis on acquiring resources suggests that the substantive/content dimension of ILTs would be particularly important during this stage. Quinn and Cameron go on to suggest that securing cooperation and commitment become more important during the growth stage. The symbolic dimension of ILTs thus 
would be emphasized during this life cycle stage. We speculate that the substantive dimension would be most influential during the mature stage, while the symbolic dimension, would again be more important during the revitalization stage (cf. Hunt et al., 1988). Finally, as previously mentioned, Romanelli and Tushman (1988), in a related conceptualization, argue that the relative emphasis on substantive and symbolic leadership will vary according to where an organization is in its evolution.

Organizational Culture. Finally, we expect culture - this time organizational culture- to join with structure, strategy and life cycle to influence the prototypes. As Hambrick and Finkelstein (1987) note, "a strong culture defines methods of operation, thus sanctioning certain options while at the same time prohibiting others"' (p. 384).

\section{Background Variables and Prototypes}

As Figure 2 indicates, we see background variables of individuals as operating at all three prototype levels and across both domains. Of course, as we show below, we anticipate specific kinds of variables to have more impact at some levels than others. While on the surface, background variable relationships may appear straightforward, they are complicated because of their direct and indirect nature. In some cases, a given background variable may have a direct relationship with a prototype/ILT. In other cases, the relationship may be indirect-operating through perceptions of, say, the specific environment or culture. Figure 2 recognizes that either or both kinds of relationships could be operating; however, for simplicity our present discussion is couched primarily in direct relationship terms and it is left for future research to help tease out the mix of direct and indirect relationships.

The top-management and organizational behavior literatures are generally silent on the kinds of background variables likely to be important in the context of leadership prototypes. However, they do discuss background variables in other top-management contexts that for us are suggestive for our purposes. The variables tend to be divided into two broad classes - socio-demographic and personal attributes-and we shall follow suit.

Demographics. A summary literature review by Jackofsky and Slocum (1988) argues that such demographic variables as kind of school attended (e.g., public vs. private), military service (e.g., branch in which served), socio-economic status of parents and siblings, and various kinds of early childhood experiences have been found to be important in the context of top management. Kotter (1982) reports similar results. To these we add variables such as level of education, tenure and experience, gender, and age (cf. Hambrick \& Mason, 1982).

Jackofsky and Slocum indicate that at least the former kinds of variables tend to make their influence felt through values (a personal attribute to be considered shortly). Similarly, we expect that in the present context, age will operate as an indication of given cohort values to influence prototypes/ILT's. People brought up during a certain time period will tend to reflect the values of their cohorts of the same general age-e.g., "the baby boomers."

We anticipate that both the former and latter groupings of variables will have an impact at the superordinate prototype level. However, former branch of military service, gender and tenure/experience (broken down within industry and firm) are expected to be important at the basic and/or subordinate levels. The military branch and tenure relations are expected 
to reflect earlier carryover to current settings. Gender is anticipated to reflect biases concerning traditional gender-related occupational groupings (e.g., nurses).

Personal Attributes. Here, recent top management work commonly emphasizes such variables as tolerance for ambiguity, locus of control, cognitive complexity, and tolerance for stress (e.g., Hambrick \& Finkelstein, 1987; Jakofsky \& Slocum, 1988). To these we add Machiavellianism (e.g., Hambrick \& Brandon, 1988) self-monitoring (Gangestad \& Snyder, 1985) and value structure (e.g., Hambrick \& Brandon, 1988). We expect these variables to have a relatively strong impact at the basic and/or subordinate prototype levels. For example, consider the personal attributes necessary in the utility and aerospace industries. The leader prototypes in these two industries should be quite different in terms of personal attributes such as tolerance for ambiguity and locus of control.

It is beyond our present purpose to discuss further each of the above variables. However, we will briefly treat Machiavellianism, self-monitoring and values. Essentially, highMachs, as measured by one of the Mach scales (cf. Christie \& Geiss, 1970), tend to be cool and detached and to exploit loosely structured situations but to behave in a perfunctory or even detached manner in tightly structured situations. Low Machs tend to accept direction from others where there is loose structure and to work hard to perform well where there is tight structure. High Machs tend to be amoral and will do whatever it takes to complete what they perceive as an important job. We suggest that the nature of the leader-follower Mach combination will influence prototype match at the subordinate level (cf. Hunt \& Osborn, 1976).

Turning now to self monitoring, Gangestad and Snyder (1985) have demonstrated that people differ significantly in the degree to which they monitor and respond to their environment. These authors suggest that low self-monitors tend to behave in the same way regardless of situational demands. In terms of the three levels and two prototype domain dimensions, such individuals may maintain their ILT prototype irrespective of industry and organization. In other words, these individuals are likely to develop leader category prototypes that are consistent with universal trait or behavioral approaches to leadership (e.g., Bass, 1981). Clearly, some current popular literature (e.g., Peters \& Waterman, 1982) suggests a one-best-way approach which we believe would be reflected in the prototypes of low self-monitors.

In contrast, Gangestad and Snyder (1985) suggest that high self-monitors vary their behaviors (and by extension-prototypes) as a function of the situation within which they are embedded. We believe these individuals would be more likely to develop the kind of contingency-based prototypes specified at the basic and subordinate levels.

Finally, Hambrick and Brandon (1988) provide us with a discussion of top management values that has implications for prototypes-especially at the basic and subordinate levels. From an extensive review of the literature on values, they develop a set of six top management value dimensions they contend are likely to be of special importance (see Hambrick \& Brandon, 1988, p. 14). These are:

Collectivism: Value wholeness of human-kind and of social systems; regard and respect for all people.

Duty: Value integrity of reciprocal relationships; obligation and loyalty.

Rationality: Value fact-based, emotion-free decisions/actions.

Novelty: Value change, the new and different. 
Materialism: Value wealth/pleasing possessions.

Power: $\quad$ Value control of situations/people.

\section{CONCEPTUAL AND RESEARCH ASPECTS OF PROTOTYPE MATCHES}

To this point we have: (1) argued for the importance of three different levels (superordinate, basic and subordinate) and two different domain dimensions (substantive/content and symbolic/process) of leadership prototypes; (2) hypothesized that environmental, organizational and individual background variables differentially influence the development of prototypes at each of these levels and domains; and (3) asserted that a match or mismatch between a subordinate's prototype of a leader, real leader or effective leader and characteristics of the leader in question would have an impact on various personal and organizational outcomes. Now we would like to extend the discussion of our prototype match notion. First, we develop a detailed discussion of the substantive/content and symbolic/process domain aspects shown in the middle portion of Figure 2 and elaborate upon with the four-fold classification shown in Figure 3. Then, we discuss the match notion in terms of the outcomes in the right hand portion of Figure 2 and explicate it both conceptually and empirically in terms of temporalness, kind of match and application.

\section{Domain Illustration of Match}

The four-fold classification in Figure 3 shows ways in which leaders might be classified in the minds of their subordinates. Here, we emphasize leaders who are already in place, but the arguments are also relevant in selection of leaders.

In domain terms, the extent to which a person is considered a leader depends on how well he or she is perceived to match symbolic/process and substantive/content prototypes. The "hero" matches both the substantive/content and symbolic/process prototypes. Lee Iaccoca is an example of the hero. He has content expertise within the automobile industry but also is perceived as a symbolic/process leader - he knows how to marshall support. Because the hero matches both process and content prototypes, he or she also matches all three prototype levels (superordinate, basic, and subordinate) depicted in Figure 2. Moreover, the hero is perceived by followers as meeting prototypical demands of a leader within the organization, the industry, and outside the organization.

However, even the perception of heroes may change. The evaluation of the leader is dependent on the setting and the person evaluating him/her. Changes in setting or circumstances may mean the leader is no longer perceived as a content expert. For instance. Patton matched the wartime but not the peacetime leader prototype (Farago, 1981).

The person who matches the content but not the process prototype is the "technocrat." This type of leader is a respected expert, but does not exhibit the symbolic/process characteristics of leadership valued by the culture in general. Figure 3 suggests that these individuals may largely match the subordinate prototype and partially match the basic prototype. Such a leader may be promoted from within an organization because of his/her expertise. However, the person's perception as a leader is likely to be limited to his or her technical content area. 


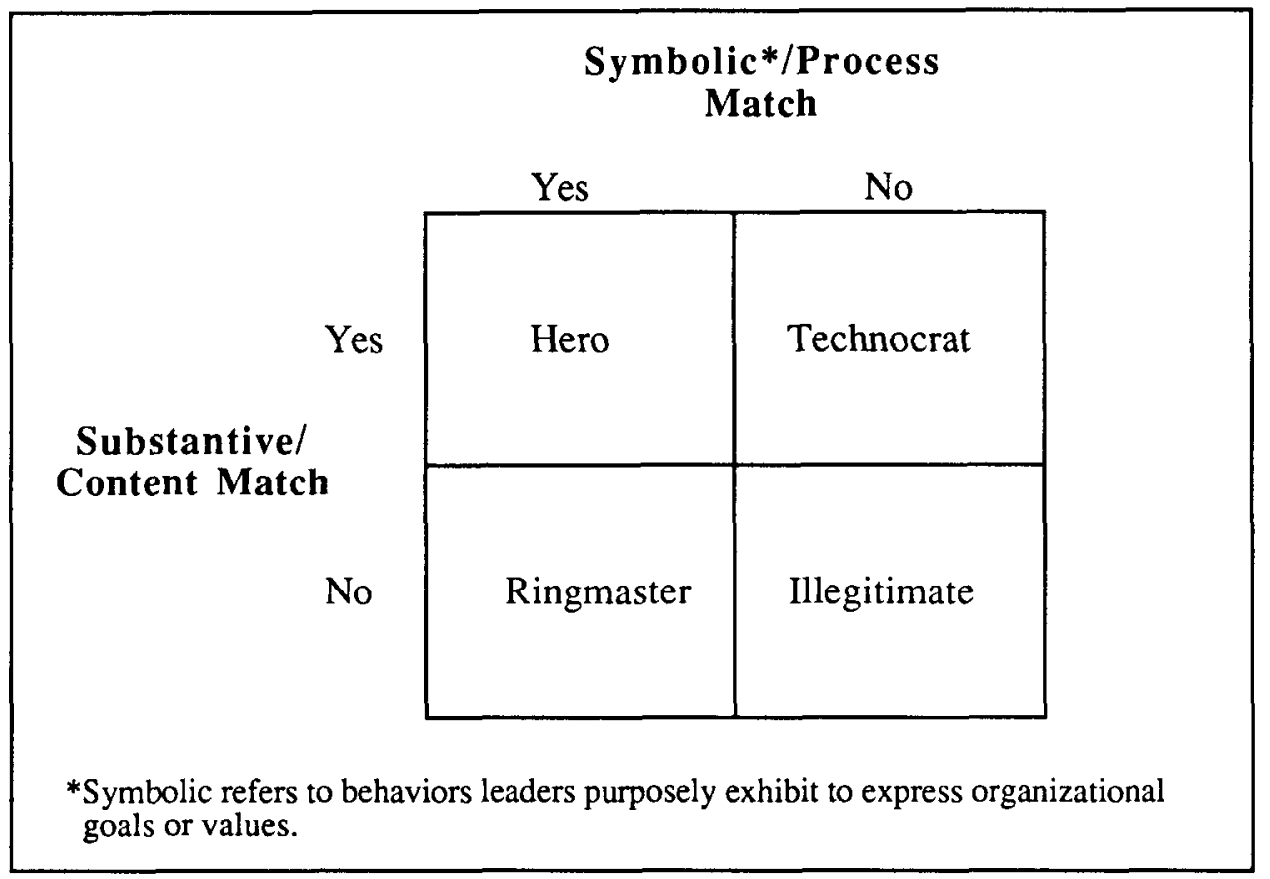

\section{Figure 3: Categorization of Leaders When They are Perceived to Match Symbolic/Process and/or Substantive/Content Prototypes}

Since higher positions in organizations require managers to interact frequently outside their content specialty with many people inside and outside the organization, technocrats may not be perceived as effective organization-wide or industry leaders. A good example of a technocrat might be former President Jimmy Carter. Former Speaker of the House, Tip O'Neil is reported as saying that Jimmy Carter was the smartest President he had ever known. However, it was widely suggested in the press, especially after his speech dealing with our "national malaise," that President Carter was not very "Presidential", because he lacked or could not communicate a vision of the future. President Carter, as an emplar of the technocrat, might be compared to the forester who could name every tree but who could not tell one what forest he was in.

In contrast, leaders who match the process but not the content prototype are called "ringmasters". These leaders are perceived to have both transactional and transformational leader characteristics (Bass, 1985), but little content expertise. The Wall Street Journal (1989), for example, describes the problems with charismatic leaders who "aren't very good at their jobs' because they got there more on charm than . . . skill . . .". Turning back to Figure 2, we suggest that even though ringmasters do not match the content prototype, they may still largely match superordinate and basic prototypes. Thus, a leader can be a "rent an executive" who knows little about a particular business, but has leadership skills which enable followers to label him or her a leader.

Unlike technocrats, ringmasters are not perceived as leaders in a content area, but may 
be perceived as leaders in a broad variety of contexts. Like the ringmaster in the circus, who herself cannot perform any of the acts, she can set the stage and orchestrate the diverse activities into a cohort whole. Judging by remarks attributed to Speaker O'Neil and to discussion in Smith (1988), former President Reagan would fit the prototype of the ringmaster. Again using a forester analogy, it might be said of President Reagan, that while he could not tell the difference between a tree and a "Bush," he knew where he was going. Such leaders undoubtedly must rely on those with content expertise to provide the content leadership in an organization. But with the right mix of subordinates the ringmaster could be as effective as the hero leader.

The "illegitimate" leader matches neither prototype. Such individuals are perceived to know little or nothing about their industry and to have few leadership characteristics. Subordinates probably attribute the leader's position to "illegitimate" influence such as a political or family appointment. Thus, individuals considered illegitimate leaders would not be expected to have the favorable kind of influence granted to the three other kinds of leaders

While we have here focused on the domain match, ignoring the previously discussed match by prototype level, the slanted line in Figure 2 shows them to be related. For example, at the very specific subordinate prototype level, content emphasis is expected to be more important than at the more general subordinate prototype level. Also, while the figures and discussion might imply an almost deterministic separate treatment of each level and domain, we assume that these operate simultaneously in the subordinates' mind.

\section{Personal and System Responses to Match}

We expect at least two major responses to occur when leaders match follower prototypes (see right hand portion of Figure 2). First, human resource maintenance variables should be enhanced. Subordinates who perceive such a match are more satisfied with and committed to leadership in the organization. Second, implementation of strategy is more successful, improving individual subordinate performance and organizational effectiveness. We assume where subordinates' leadership prototypes are influenced by strategy and they perceive a prototype match, they will be committed to the strategy in question and put forth the effort to carry it out.

On the other hand, when individuals do not perceive a match, individual performance may either decline or individual efforts may be at variance with those of the superior. In either case, individual performance may be less than optimal. Also, we expect the substantive/content dimension to influence performance/effectiveness more strongly and the process domain more strongly to influence human resource outcomes. We should further note that measures of organizational effectiveness should reflect the nature of the primary strategic thrust. Thus, the relevant measures would be expected to differ for high growth, as opposed to high profit and/or turnaround strategies (see, e.g., Korhonen, Santalainen \& Tainio, 1987). Such a thrust is consistent with recent treatments of the organizational effectiveness literature (e.g., Cameron, 1986).

\section{Conceptual and Empirical Explication}

The explication in this section demonstrates that the match notion is more complex than it first appears and helps clarify the concept both conceptually and empirically. 
Conceptually, we start by recognizing that the match notion is a dynamic one. As circumstances, settings, and individuals change the match also changes. Consider Gary Hart, Richard Nixon, and Winston Churchill. Although all were considered competent and had positive attributes, changes in their actions or circumstances resulted in a symbolic/process prototype mismatch. Within a few days, Hart changed from front-runner for the presidential nomination to noncandidate. After Watergate, Nixon was forced out of office. And, as Winston Churchill in essence is reported to have said, "The war being successfully concluded, I was promptly voted out of office."

Consider further the case of the rise and fall of People Express (People Express, 1983; Texas Monthly, 1987). Donald Burr's opportunity to found an airline arose from the airline Deregulation Act of 1980 which allowed newcomers, such as Burr, to enter the industry. He initiated strategy combining short hauls, low fares, and low formalization with an emphasis on employee development. We conjecture that this strategy influenced prototypes of Burr's immediate subordinates, among others, and their perceptions of the match between such prototypes and Burr's leadership.

People Express grew rapidly both from Burr's initial strategy and from acquisition. As People Express and the market changed and competition became stiffer (changing aspects of the environment), Burr failed to adjust his strategy, including continued deemphasis on formalization, in an increasingly complex situation. Not surprisingly, People faltered and was taken over by Texas Air. We speculate that his immediate subordinates changed their prototypes, thus disrupting the former match between prototypes and leadership.

Kind of Match. In addition to dynamism an important concern, both conceptually and empirically, is the kind of match. Although we have used the term "match," the concept is really a form of what Venkatraman (1989) calls "fit." He makes the very important point that fit has typically been used in the strategic management literature without the users' being aware of the different conceptual and empirical forms that it can take. That argument also appears relevant for the leadership literature. He compares and contrasts six such forms in terms of their theoretical meanings and appropriate analytical schemes.

For our purposes, three of these appear most relevant. The first of these, fit as moderation or interaction, is probably the best known of the three. The previously discussed four-cell matrix focusing on the hero, ringmaster, technocrat and illegitimate prototypes and their relation to assessment as a real or effective leader is an illustration of Venkatraman's fit as moderation category. Essentially, one is arguing that the relationship between a given prototype domain dimension and the criterion is moderated by another domain dimension. Venkatraman indicates that analysis of variance, subgroup analysis and moderated regression (actually an analog to analysis of variance; McNeil, Kelly \& McNeil, 1975) are all relevant analytical techniques here, but that both theoretical and statistical considerations will influence the final decision concerning the technique(s).

Based on the above discussion, fit as moderation does, indeed, appear appropriate here, given that Venkatraman's qualifications are considered. However, it makes the very important assumption of using no more than two variables plus a criterion. That assumption leads us to favor two of his other fit perspectives-fit as gestalts and fit as profile deviation. Each of these perspectives is capable of using many variables, whereas, the moderation approach would have to collapse, in some manner, the number of leadership dimensions into overall measures of substantive/symbolic leadership. Thus, the richness of the analysis would be restricted. 
Gestalt and profile deviation analyses are consistent with recent emphases on configurations, archetypes, taxonomies and the like (see Hambrick, 1984; Miller \& Friesen, 1980; Miller \& Mintzberg, 1983). In using these, the assumption is that holistic patterns of variables more accurately reflect true relationships than do a series of bivariate analyses or even multiple regressions. Put another way, equifinality is assumed to be operating.

The gestalt perspective is less precise than the profile deviation perspective. The former simply considers ... "frequently recurring clusters of attributes of gestalts" (Miller, 1981 , p. 5). The latter calls for . . " "degree of adherence to an externally specified profile . . .' (Venkatraman, 1989, p. 433). At our current state of knowledge, we believe that the gestalt perspective is the more realistic of the two approaches but that as knowledge increases we may be in a position to utilize the more precise profile deviation approach.

One recent illustration of a gestalt approach in the leadership literature is that of Quinn (1988) who wanted to find out patterns of leadership role emphasis or leadership role archetypes for effective versus ineffective leaders where there were eight leadership roles. He selected very high and very low performing subsamples and used cluster analysis for each of the subsamples. He then plotted the scale scores for the clusters in circular form based on standard deviations corresponding to the second, sixteenth, fiftieth, eighty-fourth and ninety-eighth percentiles $(-2,-1,0,+1,+1$ SD's, respectively). From this he derived six different profiles for "effectives" and seven different profiles for "ineffectives." Such cluster analysis is one recommended analytic technique along with others such as Q-factor analysis discussed by Miller (1978).

For our purposes, any technique is complicated because we are not simply using a single set of variables as was Quinn, but first must obtain some kind of score based on the relationship between a prototype measure and a measure of perceived leader behavior. Here a couple of candidates are the deviation score analysis and the residual analysis.

In the deviation score analysis, the absolute difference between the standardized scores of two variables is interpreted as a lack of fit. Venkatraman (1989) points out a number of problems with this kind of analysis and assesses its potential usefulness. Residual analysis uses the residuals from the regression of one variable (e.g., X) on the other (e.g., Z) which provides scores that can be related to the criterion. Again, Venkatraman assesses the overall usefulness of the approach. Miller (1978) and Cronback and Furby (1970) also discuss the previous measures as well as others and Kerlinger and Pedhazur (1973) discuss residualization in some detail.

Application. Let us see how the previous discussion might apply to the prototype matching in our model. First, one would measure the CEO's subordinates' leadership prototypes. Lord and his colleagues have examined the measurement of prototypes in some detail across a range of studies. The Akron Leadership Qucstionnaire (ALQ) (see Lord, et al, 1984) appears particularly relevant here. It consists of 25 items, with some of these previously rated as being prototypical ("fits my image of a leader extremely well"'), some as neutral, and some as antiprototypical. ${ }^{3}$ While these ratings provide some insight as to prototype evaluations of previous samples they also can be assessed for each new sample. Some items are: emphasizes goals, talks frequently, agrees readily and neglects details. The ALQ would provide the symbolic/process domain content. Then, a leader expertise measure, such as that discussed in Podsakoff, Todor and Schuler (1983), could be used to connote the substantive/content domain aspect.

Next, the CEO's perceived leader behavior would be described. This could be done 
using the ALQ and expertise prototype items with different descriptors (e.g., "extent to which my CEO exhibits this behavior") or one of the questionnaires designed to tap descriptions of leader behavior could be used along with an expertise measure. Where one of the leader behavior instruments is used, our preference is for Yukl's (1989) measure because of its careful conceptual and psychometric development. While the dimensions/items are not identical to those in the ALQ, a residualization process between prototypes and behavior descriptions would not necessitate identical measures. An alternative prototype measure that would provide for identical dimensions/items would be to use Yukl's questionnaire (with appropriate descriptors) for both prototype and leader behavior descriptions. One version of that instrument has specific items which are combined to form 13 dimensions. Another version, that trades off some specificity for convenience, asks people to respond to summary descriptions of each of his 13 dimensions.

We should note that the prototype measure here includes implicitly the earlier superordinate, basic and subordinate levels. This is because evaluation of the prototypically of the items is influenced by the organizational context which, as previously indicated, includes all three levels.

Given that we have prototype descriptions and perceptions of the leader's behavior and that we have derived match scores through some appropriate method referenced earlicr, we can now use some version of cluster analysis (cf. Hambrick, 1984; Quinn, 1988) to relate these to the criterion of interest. In terms of the model shown in Figure 2 that would first involve human resource maintenance and performance/effectiveness.

Quinn's procedure of using cluster analysis to look for configurations for those highest and lowest on the criterion in question would be appropriate. The configurations would be based on the previously discussed match scores. The hypothesis essentially would be that the configurations not only would differ between high and low outcome segments but that the high outcome segments would be based primarily on matches among prototypical variables (as previously indicated from initial expression of how much an item in question fitted the respondent's image of a leader). Conversely, the low outcome segment would tend to emphasize clusters based on neutral or antiprototype matches.

While the emphasis above is on the criteria in Figure 2, another possibility is the General Leadership Impression (GLI) measure of Cronshaw and Lord (1987). The GLI has been used as a dependent variable measuring the extent to which one is seen as a real leader after the fact. Indeed, we see this variable as an intervening one between match and the right hand criteria in Figure 2 , but for simplicity we did not include it. Other variables, similar to GLI, could also be utilized.

Finally, there is the question of the temporal emphasis. We pointed out its importance earlier. Venkatraman $(1989$, p. 441) cautions us that, . . " it is unclear whether the six perspectives identified [in his article] are appropriate for testing [dynamic matches]." However, as Miller (1981) indicates, one can do a series of comparative static analyses.

\section{CONCLUDING COMMENTS}

This article is basically a conceptual one which we hope will encourage researchers to extend the investigation of leadership prototypes from the laboratory to the top organizational levels (with a particular emphasis on the CEO and his/her immediate subordi- 
nates). As such, we encourage people to try to test various aspects of the model, empirically. While we have tried to be specific enough to provide empirical guidance, we have shied away from being very specific at this stage of the model, with the exception of our explication of the match notion. Rather, we have tried to make the model specific enough to encourage its testing (realistically in most cases that probably will involve only partial tests). Put another way, in general, we encourage creativity in operationalizing the variables. We have been more specific concerning the match because it is a relatively complex notion that, as we pointed out, appears deceptively simple. However, even here we encourage creative testing.

Also, it almost goes without saying, that we have just scratched the surface on the issues that could be investigated within the context of the model in its present form or extended to include other variables. One key illustrative issue that comes to mind is the notion of match across the CEO's subordinates. To now, we have considered the match on an individual basis, but obviously that should be extended to look at consistency in match among the subordinates. We close by inviting the reader to consider other such issues.

\section{NOTES}

1. These loosley correspond to Mintzberg's (1983) typology as follows: 1) hierarchical systems = instrument or closed system; 2) professional = meritocracy; 3) task = autocracy; and 4) group = missionary. We utilize Miner's model, instead of Mintzberg's, because of the greater amount of research on his typology.

2. We chose Miles and Snow's typology for illustrative purposes. Porter (1980) has also recently proposed another typology of generic strategies using the dimensions of cost leadership, product differentiation, and focus. Research by Parks (1985) suggests that prospectors follow a differentiation strategy, defenders a focus strategy, analyzers a combination of focus and differentiation strategies, while reactors resemble stuck-in-the-middle firms.

3. Lord et al (1984) do not simply use prototypical items. They include neutral and antiprototypical items as well. Thus, the nature of the match is broadened to recognize that a match of prototypical items and perceived leadership would be desirable, while that of neutral and antiprototypical items would have neutral and undesirable consequences, respectively. We recognize such a differentiation in our subsequent discussion.

\section{REFERENCES}

Astley, W. G. (1985) The two ecologies: Population and community perspectives on organizational evolution. Administrative Science Quarterly, 30, 224-241.

Baliga, B. R., \& J. G. Hunt. (1988). An organizational life cycle approach to leadership. In Emerging leadership vistas edited by J. G. Hunt, B. R. Baliga, H. P. Dachler, and C. A. Schriesheim, pp. 125-149. Lexington, MA: Lexington Books.

Bass. B. M. (1981). Stogdill's handbook of leadership. New York: Free Press. (1985). Leadership: Good, better, best. Organizational Dynamics, Winter, pp. 26-40.

Boal, K. B. \& R. E. Willis (1983). A note on the Armstrong/Mitroff debate. Journal of Management, 9. 103-21.

Borman, W. C. (1983). Implications of personality theory and research for the rating of work 
performance in organizations. In R. Landy, S. Zedeck and J. Cleveland (Eds.), Performance measurement and theory. Hillsdale, NJ: Erlbaum.

(1987). Personal constructs, performance schemata, and 'folk theories' of subordinate effectiveness: Explorations in an army officer sample. Organizational Behavior and Human Decision Processes, 40, 307-322.

Burns, T., \& G. M. Stalker. (1961). The management of innovation. London: Tavistock.

Cameron, K. (1986). Effectiveness as paradox. Management Science, 32, 539-553.

Cantor, N., E. E. Smith, R. French \& J. Mezzich. (1980). Psychiatric diagnosis as prototype categorization. Journal of Abnormal Psychology 89, 181-193.

Christie, R. \& F. L. Geis. (1970). Studies in Machavellianism. Orlando, FL: Academic Press.

Cronbach. L. J. \& L. Furby. (1970). How should we measure 'change'-or should we? Psychological Bulletin, 74, pp. 68-80.

Cronshaw, S. F. \& R. F. Lord. (1987). Effects of categorization, attribution, and encoding processes on leadership perceptions. Journal of Applied Psychology, 72, 97-106.

Cyert, R. M. \& J. C. March. (1963). A behavioral theory of the firm. Englewood Cliffs, NJ: Prentice Hall.

Dalton, D. R. \& I. F. Kesner. (1985). Organizational performance as an antecedent of inside/outside chief executive succession: An empirical assessment. Academy of Management Journal, 28, 749-762.

Day, D. V. \& R. G. Lord. (1988). Executive leadership and organizational performance: Suggestions for a new theory and methodology. Journal of Management, 14, 453-464.

Dill, W. R. (1958). Environment as an influence on managerial autonomy. Administrative Science Quarterly, 2, pp. 409-443.

Duck, S. W. (1982). Two individuals in search of agreement: The commonality corollary. In J. C. Mancuso and J. R. Adams-Webber (Eds.), The construing person. New York: Praeger.

Duncan, R. B. (1972). Characteristics of organizational environments and perceived environmental uncertainty. Administrative Science Quarterly, 3, 313-327.

Eden, D. \& V. Leviation. (1975). Implicit leadership theory as a determinant of the factor structure underlying supervisory behavior scales. Journal of Applied Psychology, 60, 736-740.

Eshghi, G. (1985). Nationality bias and performance evaluations in multinational corporations. Academy of Management Proceedings, 93-97.

Farago, L. (1981). The last days of Patton. New York: Berkley.

Farris, G. F. \& D. A. Butterfield. (1973). Are current theories of leadership culture bound? An cmpirical tcst in Brazil. In Current developments in the study of leadership edited by $\mathrm{E}$. A. Fleishman and J. G. Hunt, pp. 105-138. Carbondale, IL: Southern Illinois University Press.

Filley, A. C. \& R. J. Aldag. (1978). Characteristics and measurement of an organizational typology. Academy of Management Journal, 21, 578-591.

Fortune (1989). America's ten worst bosses, February 27.

Gangestad, S. \& M. Synder. (1985). To carve nature at its joints: On the existence of discrete classes in personality. Psychological Review, 92, 317-349.

Gardner, H. (1985). The mind's new science. New York: Basic Books

Gerstein, M. \& H. Reisman. (1983). Strategic selection: Matching executives to business conditions. Sloan Management Review, Winter, 33-49.

Gioia, D. A. \& P. P. Poole. (1984). Scripts in organizational behavior, Academy of Management Review, 9, 449-459.

Gupta, A. \& V. Govindarajan. (1982). An empirical examination of linkages between strategy, managerial characteristics, and performance. Academy of Management Proceedings, pp. 31-35.

Hambrick, D. J. (1984). Taxonomic approaches to studying strategy: Some conceptual and methodological issues. Journal of Management, 10 (1), $27-42$.

Hambrick, D. C. \& G. L. Brandon. (1988). Executive values. In The executive effect: Concepts 
and methods for studying top managers, edited by D. C. Hambrick, pp. 3-34. Greenwich, CT: JAI Press.

Hambrick, D. C. \& S. Finkelstein. (1987). Managerial discretion: A bridge between polar views of organizational outcomes. In Research in organizational behavior, edited by L. L. Cummings and B. M. Staw, Vol. 9 pp. 369-406. Greenwich, CT: JAI Press.

Hambrick, D. C. \& P. A. Mason. (1982). The organization as a reflection of its top managers. Academy of Management Proceedings, pp. 12-16.

Hastie, R. (1981). Schematic principles of human memory. In Social cognition: The Ontario Symposium, edited by E. T. Higgins, C. A. Herman and M. P. Zana, Vol. 1. Hillsdale, NJ: Erlbaum.

Herbert, T. T. \& H. Deresky. (1987). Should general managers match their business strategies? Organizational Dynamics, Winter, pp. 40-51.

Hofer, C. W. (1980). Turnaround strategies. Journal of Business Strategy, 1, 19-31.

Hofstede, G. (1980). Culture's consequences: International differences in work related values. Beverly Hills, CA: Sage.

Hofstede, G. (1976). Nationality and espoused values of managers. Iournal of Applied Psyrhology, $61,148-155$.

Hornstein, H., M. Heilman, E. Mone, \& R. Tartell. (1987), Responding to contingent leadership behavior. Organizational Dynamics, Spring pp. 56-65.

House, R. J. \& M. Baetz. (1979). Leadership: Some generalizations and new research directions. In Research in organizational behavior, edited by B. M. Staw \& L. L. Cummings Vol. 1 pp. 341-423. Greenwich, CT.: JAI Press.

Hunt, J. G., B. R. Baliga, \& M. F. Peterson (1988). Strategic apex leader scripts and the organizational life cycle. Journal of Management Development, 7 (5), 61-83.

Hunt, J. G. \& Osborn, R. N. (1976). Machiavellianism: The manipulative side of leadership. Southwest Division, Academy of Management 1976 Proceedings, 73-77.

Hunt, J. G., R. N. Osborn \& H. J. Martin (1983). A multiple influence model of leadership. Alexandria, VA: U. S. Army Institute for the Behavioral and Social Sciences.

Jacobs, T. O. \& E. Jaques. (1989 in press). Leadership in complex systems. In Human productivity enhancement. Vol 2: Organizations and personnel, edited by J. A. Zeidner. New York: Praeger.

Jakofsky, E. F. \& Slocum, J. W., Jr. (1988). CEO roles across cultures. In The executive effect: Concepts and methods for studying top managers, edited by D. C. Hambrick, pp. 67-100. Greenwich, CT: JAI Press.

Jurkovich, R. (1974). A core typology of organizational environments. Administrative Science Quarterly, 19, 380-394.

Kerlinger, F. N. \& E. J. Pedhazur. (1973). Multiple regression in bchavioral research. New York: Holt, Rinehart and Winston.

Kimberly, J. R. \& R. E. Quinn. (1984). Managing organizational transitions. Homewood, IL: Irwin.

Korhonen, P. T., T. Santalainen, \& R. Tainio. (1987). Explaining variations in work performance. Working paper \#168, Helsinki School of Economics.

Korukonda, A. R. \& J. G. Hunt. (1989). Pat on the back vs. kick in the pants: An application of cognitive inference to the study of leader reward and punishment behaviors. Group and Organization Studies, 14, 299-334.

Kotter, J. P. (1982). The general managers. Ncw York: Frec Press.

Kunda, A. (1987) Motivated inference: Self-serving generation and evaluation of causal theories. Journal of Personality and Social Psychology, 53, 636-647.

Lammers, C. J. \& D. J. Hickson. (1979). Towards a comparative sociology of organizations. In 
Organizations: Alike and unlike, edited by C. J. Lammers and D. J. Hickson. London: Routledge \& Kegan Paul.

Lord, R. G. (1985). An information processing approach to social perception, leadership perceptions and behavioral measurement in organizational settings. In Research in organizational behavior. edited by L. L. Cummings and B. M. Staw Vol. 7 pp. 87-128. Greenwich, CT: JAI Press.

Lord, R. G. \& R. J. Foti. (1986). Schema theories, information processing, and organizational behavior. In The thinking organization, edited by H. P. Sims and D. A. Gioia, pp. 20-48. San Francisco: Jossey-Bass.

Lord, R. G., R. J. Foti, \& D. L. DeVader. (1984). A test of leadership categorization theory: Internal structure, information processing and leadership perceptions. Organizational Behavior and Human Performance, 34, 343-378.

Lord, R. G., R. J. Foti, \& J. S. Phillips. (1982). A theory of leadership categorization. In Leadership: Beyond establishment views edited by J. G. Hunt, V. Sekaran and C. A. Schriesheim, pp. 104-121. Carbondale, IL: Southern Illinois University Press.

Lowin, A. \& J. R. Craig. (1968). The influence of level of performance on managerial style: An experimental object-lesson in the ambiguity of correlational data. Organizational Behavior and Human Performance, 3, 440-458.

Lubatkin, M. \& K. Chung. (1985). Leadership origin and organizational performance in prosperous and declining firms. Academy of Management Proceedings, pp. 25-29.

Malekzadeh, A. R. \& A. Naharandi. (1987). The fit between strategy and culture in mergers. Academy of Management Proceedings, pp. 4l-45.

McKelvey, B. (1982). Organizational Systematics: Taxonomy, evolution. classification. Berkeley, CA: University of California Press.

McNeil, K. A., F. J. Kelly, \& J. T. McNeil. (1975). Testing research hypotheses using multiple linear regression. Carbondale, IL: Southern Illinois University Press.

Meindl, J. R., S. B. Ehrlich \& J. M. Dukerich. (1985). The romance of leadership. Administrative Science Quarterly, 78-102.

Meindl, J. R. \& S. B. Ehrlich. (1987). The romance of leadership and the evaluation of organizational performance. Academy of Management Journal, 91-109.

Miles, R. E. \& C. C. Snow. (1978). Organizational strategy, structure and processes. New York: McGraw-Hill.

Miller, D. (1978). The role of multivariate Q-techniques in the study of organizations. Academy of Management Review, 21, pp. 515-531.

Miller, D. (1981). Toward a new contingency perspective: The search for organizational gestalts. Journal of Management Studies, 18, 1-26.

Miller, D. \& P. H. Friesen. (1980). Archetypes of organizational transition. Administrative Science Quarterly, 25, 268-299.

- (1982). The longitudinal analysis of organizations: A methodological perspective. Management Science, 28, 1013-1034.

Miller, D. \& H. Mintzberg. (1983). The case for configuration. In Beyond Method, edited by G. Morgan, pp. 45-56. Newbury Park, CA: Sage.

Miner, J. B. (1980). Limited domain theories of organizational energy. In Middle range theory and the study of organizations, edited by C. C. Pinder and L. F. Moore, pp. 273-286. Boston: Martinus Nijhoff.

- (1982). The uncertain future of the leadership concept: Revisions and clarifications. Journal of Applied Behavioral Science, 18, 293-307.

- (1984). The validity and usefulness of theories in an emerging organizational science. Academy of Management Review, 9, 296-306.

Mintzberg, H. (1983). Power in and around organizations. Englewood Cliffs, NJ: Prentice-Hall. 
Mischel, W. (1977). The interaction of person and situation. In Personality at the crossroads: Current issues in interactional psychologv, edited by D. Magnusson and H, S. Endler. Hillsdale, NJ: Erlbaum.

Morrison, A. J, \& A. Bauerschmidt. (1987). Organizational life cycles: A comprehensive approach. Forty-seventh annual meeting of the Academy of Management, New Orleans, August.

Nisbett, R. \& L. Ross (1980). Human inference: Strategies and shortcomings of social judgment. Englewood Cliffs, NJ: Prentice-Hall.

Osborn, R. N., J. G. Hunt \& L. R. Jauch. (1980). Organization theory. New York: Wiley.

Parks. D. M. (1985). An empirical examination of the relationship between the strategic typologies proposed by Miles and Snow, Porter, and Hall. Southern Management Association Proceedings, pp. 4-6.

People Express (1983). Harvard Business School Case 9-48 pp. 3-103, Harvard Business School. Cambridge, MA.

Perrow, C. (1979). Complex organizations: A critical essay. Glenview, IL: Scott, Foresman.

Peters, T. J. \& R. H. Waterman. (1982). In search of excellence. New York: Harper \& Row.

Podsakoff, P. M., W. D. Todor \& R. S. Schuler (1983). Leader expertise as a moderator of the effects of instrumental and supportive leader behaviors. Journal of Management, 9, 173-186.

Porter, M. E. (1980). Competitve strategy. New York: Free Press.

Pugh, D. S., D. J. Hickson, \& C. R. Hinings. (1985). Writers on organizations. Beverly Hills, CA: Sage.

Quinn, R. E. (1988). Beyond rational management. San Francisco: Jossey-Bass.

Quinn, R. E. \& K. Cameron. (1983), Organizational life cycles and the criteria of effectiveness. Management Science, 29, 63-77.

Romanelli, E. \& M. L. Tushman. (1988). Executive leadership and organizational outcomes: An evolutionary perspective. In The executive effect: Concepts and methods for studying top managers edited by D. J. Hambrick, pp. 129-146. Greenwich, CT: JAI Press.

Ronen. S. \& O. Shenken. (1985). Clustering countries on attitudinal dimensions: A review and synthesis. Academy of Management Review, 10, 435-454.

Rosch, E. (1978). Principles of categorization. In Cognition and categorization, edited by E. Rosch and B. B. Lloyd. Hillsdale, NJ: Erlbaum.

Rush, M. C., J. C. Thomas \& R. G. Lord. (1977). Implicit leadership theory: A potential threat to the internal validity of behavior questionnaires. Organizational Behavior and Human Performance, 20, 93-100.

Russell, C. J. (1987). Person characteristics versus role congruency explanations for assessment center ratings. Academy of Management Journal, 30, 817-826.

Sackett, P. R. \& G. F. Dreher, (1982). Constructs and assessment center dimensions: Some troubling findings. Journal of Applied Psychology, 67, pp. 401-404.

(1984). Situation specificity of behavior and assessment center validation strategies: A rejoinder to Neidig and Neidig. Journal of Applied Psychology, 69, 187-189.

Sandberg, W. R. (1986). New venture performance: The role of strategy and industry structure. Lexington, MA: Lexington Books.

Sathe, V. (1985). Culture and related corporate realities. Homewood, IL: Irwin.

Schermerhorn, J. R., Jr., J. G. Hunt \& R. N. Osborn (1988). Managing organizational behavior (3rd Ed.). New York: Wiley.

Schwartz K. B. \& K. Menon. (1985). Executive succession in failing fïrms. Academy of Management Journal. 8, 680-686.

Seers, A. \& G. B. Graen. (1984). The dual attachment concept: A longitudinal investigation of a combination of task characteristics and leader-member exchange. Organizational Behavior and Human Performance, 33, 283-306. 
Shetty, Y. K. \& N. S. Peery. (1976). Are top executives transferable across companies? Business Horizons, 19, 23-28.

Shweder, R. A. (1975). How relevant is an individual differences theory of personality? Journal of Personality, 43, 455-484.

(1982). Fact and artifact in trait perception: the systematic distortion hypothesis. Progress in experimental personality research. 1, 65-100.

Sims, H. P., Jr. \& Gioia, D. A. (1986). The thinking organization. San Francisco: Jossey-Bass.

Smircich, L. (1983). Concepts of culture and organizational analysis. Administrative Science Quarterly, 28, 339-358.

Smircich, L. \& C. Stubbart. (1985). Strategic management in an enacted world. Academy of Management Review, 10, 724-736.

Smith, H. (1988). The power game. New York: Ballantine Books.

Smith, K. J., J. P. Guthrie \& M. L. Chen. (1986.) Miles and Snow's typology of strategy, organizational size, and organizational performance. Academy of Management Best Paper Proceedings, pp. $45-49$.

Smith, J. \& M. C. White. (1987). Strategy, CEO specialization, and succession. Administrative Science Quarterly, 32, 263-280.

Starbuck, W. L. (1976). Organizations and their environments. In Handbook of industrial and organizational psychology, edited by M. D. Dunnette, pp. 1069-1123. Chicago: Rand McNally.

Starbuck, W. L. \& B. L. Hedberg. (1977). Saving an organization from a stagnating environment. In Strategy and structure-performance edited by $\mathrm{H}$. Thorelli pp. 249-258. Bloomington, IN: Indiana University Press.

Stewart, R. (1982). Choices for the manager. Englewood Cliffs, NJ: Prentice-Hall.

Terreberry, S. (1968). The evolution of organizational environments. Administrative Science Quarterly, 12, 950-613.

Texas Monthly (1987). Top gun, March.

The Wall Street Journal (1989). Charisma costly in the executive suite, March 21, page 1.

Thompson, J. D. (1967). Organizations in action. New York: McGraw-Hill.

Tushman, M. L. \& Romanelli, E. (1985). Organizational evolution: A metamorphosis model of convergence and reorientation. In Research in organizational behavior, edited by L. L. Cummings and B. M. Staw, Vol. 7 pp. 171-222. Greenwich, CT: JAI Press.

Vancil, R. F. (1987). A look at CEO succession. Harvard Business Review, 87 (2), pp. 107-117.

Van Maanen, J., \& S. R. Barley. (1984). Occupational communities: Culture and control in organizations. In Research in Organizational Behavior, edited by B. M. Staw \& L. L. Cummings Vol. 7 pp. 287-365. Greenwich, CT: JAI Press.

Venkatraman, N. (1989). The concept of fit in strategy research: Toward verbal and statistical correspondence. Academy of Management Review, 14, 423-444.

Wegner, D. M. \& R. R. Vallacher. (1977). Implicit psychology. New York: Oxford University Press.

Yeh, R. \& T. Sagafi-nejad. (1987). Organizational characteristics of American and Japanese firms in Taiwan. Academy of Management Best Paper Proceedings, pp. 111-115.

Yukl, G. A. (1989). Leadership in organizations (2nd Ed.). Englewood Cliffs, NJ: Prentice-Hall.

Zahra, S. A. (1985). The link between the Miles and Snow strategic types, managerial ideology, and corporate goals: An empirical investigation. Southern Management Association Proceedings, pp. 1-3. 